\title{
ANALISIS KOMPARASI BIAYA DAN PENDAPATAN USAHATANI PADA KOMODITAS PADI, KANGKUNG DAN BUNGA KINGKONG (Kasus di Kelurahan Karyamulya Kecamatan Kesambi Kota Cirebon)
}

\author{
Analysis Of Comparative Costs And Income For Rice \\ Commodities, Kangkung And Kingkong Flower (Case In \\ Karyamulya Village, Kesambi District, Cirebon City)
}

\author{
Dila Aprilia ${ }^{*}$, Amran Jaenudin $^{1}$, Dina Dwirayani ${ }^{1}$ \\ 1 Program Studi Agribisnis Fakultas Pertanian, Universitas Swadaya Gunung Jati, \\ Jl. Pemuda Raya No.32, Sunyaragi,. Kesambi, Kota Cirebon, 45132 \\ *Email: apriliadila13@gmail.com
}

\begin{abstract}
ABSTRAK
Upaya melakukan perbandingan biaya dan pendapataan usahatani pada berbagai komoditas merupakan hal penting dalam menentukan komoditas mana yang paling menguntungkan. Penelitian ini bertujuan untuk membandingkan biaya dan pendapatan usahatani pada komoditas padi, kangkung dan bunga kingkong di Kelurahan Karyamulya Kecamatan Kesambi Kota Cirebon penelitian dilakukan pada bulan Juli-September 2020. Metode penelitian menggunakan kuantitatif dengan tenik pendekatan survey. Adapun jumlah sampel ditentukan secara sengaja masing-masing sebanyak 10 responden terdiri dari petani yang berusahatani padi, 10 petani kangkung dan 10 petani bunga kingkong. Hasil penelitian menyimpulkan bahwa biaya rata-rata tertinggi pada luas lahan yang sama yaitu $100 \mathrm{~m}^{2}$ per tahun yaitu pada usahatani kangkung sedangkan pendapatan rata-rata tertinggi per luas lahan $100 \mathrm{~m}^{2}$ adalah pada usahatani bunga kingkong. Hasil produksi dari ketiga komoditi tersebut pada luas lahan yang sama tidak terlalu berbeda secara signifikan yang membedakan adalah harga jual dari komoditas tersebut. Harga jual bunga kingkong/kg nya lebih tinggi dibandingkan kedua komoditas lainnya.
\end{abstract}

Kata Kunci: Bunga Kingkong; Kangkung; Padi, Komparasi Biaya dan Pendapatan

\section{ABSTRACT}

Efforts to compare costs and farm data collection on various commodities are important in determining which commodity is the most profitable. This study aims to compare the costs and income of farming on rice, kale and kingkong flowers in Karyamulya Village, Kesambi District, Cirebon City. The research was conducted in July-September 2020. The 
research method used quantitative methods with a survey approach. The number of samples was determined intentionally, each of which consisted of 10 respondents consisting of rice farming, water spinach farming and kingkong flower farming. The results of the study concluded that the highest average cost for the same land area was $100 \mathrm{~m} 2$ per year, namely in kale farming, while the highest average income per $100 \mathrm{~m} 2$ land area was in kingkong flower farming. The production results of the three commodities on the same land area are not significantly different, the difference is the selling price of these commodities. The selling price of kingkong flowers/kg is higher than the other two commodities.

Keywords: Kale; Kingkong Flower; Rice Comparison Cost and Income

\section{PENDAHULUAN}

Padi, Kangkung dan Bunga Kingkong merupakan komoditas yang memiliki keunggulan masing-masingnya. Padi adalah tanaman pangan yang paling banyak dibudidayakan oleh petani Indonesia. (Asri, 2005) mengemukakan bahwa kebutuhan akan beras di Indonesia akan terus meningkat dari tahun ketahun sejalan dengan meningkatnya jumlah penduduk dan kesadaran masyarakat terhadap menu gizi. Padi merupakan komoditas utama dalam menyokong pangan masyarakat (Anggraini, 2013). Kangkung merupakan jenis komoditi sayuran yang memiliki nilai ekonomis tinggi dan berperan penting dalam pemenuhan berbagai kebutuhan keluarga petani. Hal ini dapat ditujukan dengan beberapa fenomena diantaranya adalah tanaman sayur kangkung tersebut berumur relatif pendek sehingga cepat dipanen, dapat diusahakan dengan mudah hanya menggunakan teknologi sederhana, dan hasil produksi sayuran kangkung cepat terserap dipasaran. Kangkung bernilai ekonomis dan mempunyai nilai gizi tinggi. Berbeda dengan padi dan kangkung keistimewaan tanaman bunga kingkong dapat dijadikan obat alternatif untuk mengobati penyakit, salah satu jenis tanamannya bunga kingkong (Impatiens balsamina L.) penduduk Indonesia biasanya menggunakan tanaman ini untuk tanaman hias (Adfa \& Kasrina, 2001). Bunga kingkong mengandung antosianin, dan kamperol sedangkan pada biji mengandung saponin, selain sebagai antioksidan yang baik juga dapat berperan sebagai antiviral dan anti mikroba dan saponin yang berfungsi sebagai antibakteri.

Ketiga jenis komoditas tersebut adalah yang banyak diusahakan di Kelurahan Karyamulya Kecamatan Kesambi Kabupaten Cirebon. Keterbatasan lahan pertanian di Kelurahan Karyamulya dari tahun ke tahun terus mengalami penurunan akibat alih fungsi lahan pertanian ke non pertanian. Lahan pertanian saat ini hanya tersisa sekitar 53,82 hektar. Lahan pertanian di Kelurahan Karyamulya dari tahun ke tahun terus mengalami penurunan, namun pengembangan sektor pertanian masih dilakukan mengingat masih banyak juga penduduk yang bermata pencaharian sebagai petani. Produksi, luas panen dari ketiga komoditas yang diusahakan di Kelurahan Karyamulya dapat dilihat dalam Tabel 1 di bawah ini 
Tabel 1. Jumlah Produksi dan Luas Panen Produksi Padi, Kangkung dan Bunga Kingkong

\begin{tabular}{|c|c|c|c|c|c|c|c|c|}
\hline \multirow[b]{2}{*}{ Kecamatan } & \multirow{2}{*}{\multicolumn{2}{|c|}{$\begin{array}{l}\text { Luas panen } \\
\text { (Ha) }\end{array}$}} & \multicolumn{6}{|c|}{ Jumlah Produksi Tanaman } \\
\hline & & & & on/ha & $\begin{array}{r}\text { Kangku } \\
\text { T }\end{array}$ & a/ha & Bunga & $\begin{array}{l}\text { Kingkong } \\
\text { Ton/ha }\end{array}$ \\
\hline Tahun & 2018 & 2019 & 2018 & 2019 & 2018 & 2019 & 2018 & 2019 \\
\hline Kesambi & 19,30 & 35 & 119,70 & 207,36 & 0,70 & 40,4 & 0,3 & 0,2 \\
\hline
\end{tabular}

Sumber: (Dinas Pangan Pertanian Kelautan dan Perikanan, 2019).

Perkembangan jumlah produksi padi pada tahun 2018 mencapai 119,70 ton/ha sedangkan pada tahun 2019 mencapai 207,36 ton/ha maka pertumbuhan produksi tersebut mengalami kenaikan. Selain komoditas padi di Kecamatan Kesambi pun beberapa masyarakat petani membudidayakan tanaman kangkung. Perkembangan jumlah produksi tanaman kangkung pada tahun 2018 mencapai 0,70 ton/ha sedangkan pada tahun 2019 mencapai 40,4 ton/ha maka pertumbuhan produksi tersebut mengalami kenaikan. Sedangkan jumlah produksi bunga kingkong mengalami penurunan dapat dilihat pada tabel diatas bahwa pada tahun 2018 mencapai 0,3 ton/ha dan pada tahun 2019 mencapai 0,2 ton/ha. Mengingat bahwa motif seseorang melakukan adalah meraih keuntungan, maka penelitian tertarik untuk meneliti tentang Analisis Komparasi Biaya dan Pendapatan Usahatani Pada Komoditas Padi, Kangkung dan Bunga Kingkong

\section{METODOLOGI}

Penelitian ini dilakukan di Kelurahan Karyamulya Kota Cirebon. Penelitian dilaksanakan pada bulan Juli hingga September Tahun 2020. Responden dalam penelitian ini sebanyak 30 petani yang terdiri dari 10 petani yang membudidayakan padi, 10 petani yang membudidayakan kangkung dan 10 petani yang membudidayakan bunga kingkong. Desain yang digunakan dalam penelitian ini adalah penelitian kuantitatif yang dijelaskan secara deskriptif. (Creswell, 2010) menyatakan penelitian kuantitatif adalah pengukuran data statistik objektif melalui perhitungan ilmiah berasal dari sampel orang-orang atau penduduk yang diminta menjawab atas sejumlah pertanyaan tentang survey untuk menentukan frekuensi dan presentase tanggapan mereka. Populasi adalah wilayah yang terdiri atas obyek/subyek yang mempunyai kualitas dan karakteristik tertentu yang diterapkan oleh peneliti untuk dipelajari dan kemudian ditarik kesimpulannya (Sugiyono, 2007). Populasi dalam penelitian ini adalah pelaku usahatani padi, kangkung dan bunga kingkong. Penentuan sampel dilakukan dengan cara purposive sampling (sengaja). Data yang digunakan yaitu data primer dan data sekunder. Definisi operasionalisasi variabel dapat dilihat pada Tabel 1. 
Tabel 1 Operasionalisasi Variabel Penelitian

\begin{tabular}{|c|c|c|c|c|}
\hline No & Konsep & Variabel & Indikator & $\begin{array}{c}\text { Satuan } \\
\text { Pengukuran }\end{array}$ \\
\hline \multirow[t]{2}{*}{1.} & $\begin{array}{l}\text { Usahatani } \\
\text { Padi }\end{array}$ & Biaya Usahatani & $\begin{array}{l}\text { a. Biaya Tetap } \\
\text { b.Biaya Variabel }\end{array}$ & Rp/Tahun/100m² \\
\hline & & $\begin{array}{l}\text { Penerimaan } \\
\text { Pendapatan }\end{array}$ & & \\
\hline \multirow[t]{2}{*}{2} & $\begin{array}{l}\text { Usahatani } \\
\text { Kangkung }\end{array}$ & Biaya Usahatani & $\begin{array}{l}\text { a. Biaya Tetap } \\
\text { b. Biaya Variabel }\end{array}$ & $\mathrm{Rp} /$ Tahun/100m² \\
\hline & & $\begin{array}{l}\text { Penerimaan } \\
\text { Pendapatan }\end{array}$ & & \\
\hline \multirow[t]{2}{*}{3.} & $\begin{array}{l}\text { Usahatani } \\
\text { Bunga } \\
\text { Kingkong }\end{array}$ & $\begin{array}{l}\text { Biaya Usahatani } \\
\text { Penerimaan }\end{array}$ & $\begin{array}{l}\text { a. Biaya Tetap } \\
\text { b. Biaya Variabel }\end{array}$ & Rp/Tahun/100m² \\
\hline & & Pendapatan & & \\
\hline
\end{tabular}

\section{HASIL DAN PEMBAHASAN}

Kelurahan Karyamulya merupakan salah satu Kelurahan di Kecamatan Kesambi yang masih membudidayakan usahatani padi, kangkung dan bunga kingkong. Penanaman padi dilakukan dua kali dalam satu tahun. Musim Tanam I antara bulan November- Januari dan musim tanam II antara bulan Mei-Juli. Petani dikelurahan karyamulya menggunakan pola tanam jajarlegowo. Varietas padi umumnya yang ditanam adalah Ciherang, Inpari, dan Mitongga. Harga padi kering yaitu $\mathrm{Rp} 5.000 / \mathrm{Kg}$. Sistem budidaya di Kelurahan Karyamulya dimulai dari penyiapan lahan dengan cara pengairan lahan, pengolahan lahan dengan cangkul ataupun bajak menggunakan traktor. Selain padi petani di Kelurahan Karyamulya menanam kangkung. Penanaman kangkung dilakukan 10-11 kali panen dalam 1 tahun. Benih yang digunakan adalah benih kangkung darat yang dibeli di toko pertaniaan. Harga kangkung yaitu Rp 4.000/Kg. Benih merek Bangkok LP-1 Cap Panah Merah karena selain memiliki harga yang murah, benih tersebut juga memiliki kualitas yang sangat bagus. Persiapan lahan dilakukan dengan tujuan untuk memperoleh hasil produksi yang baik. Tanaman lain yang dibudidayakan oleh petani adalah bunga kingkong. Penanaman bunga kingkong dilakukan 4 kali panen dalam 1 tahun. Harga bunga Kingkong Rp 20.000/Kg karena bunga kingkong merupakan bunga yang sangat langka. Petani biasanya menjual bunga kingkong ke pasar Kalitanjung. Pupuk yang digunakan petani dalam berusahatani bunga kingkong diantaranya pupuk Urea, KCL, Phonska, dan Pupuk Kandang. Pemupukan dilakukan agar dapat menyuburkan tanaman, biasanya petani mencampur jenis pupuk tersebut sehingga reaksinya sangat cepat dan tanaman menjadi subur. Karakteristik responden dalam penelitian dapat dilihat dalam Tabel 2 di bawah ini. 
Tabel 2. Karakteristik Responden

\begin{tabular}{|c|c|c|c|c|}
\hline No & $\begin{array}{c}\text { Karakterstik } \\
\text { Responden }\end{array}$ & $\begin{array}{l}\text { Petani } \\
\text { Padi } \\
\text { (orang) }\end{array}$ & $\begin{array}{c}\text { Petani } \\
\text { Kangkung } \\
\text { (orang) }\end{array}$ & $\begin{array}{l}\text { Petani Bunga } \\
\text { Kingkong } \\
\text { (orang) }\end{array}$ \\
\hline \multirow[t]{3}{*}{1} & Umur (Tahun) & & & \\
\hline & $15-64$ & 7 & 7 & 6 \\
\hline & $<64$ & 4 & 3 & 4 \\
\hline \multirow[t]{3}{*}{2.} & Pendidikan & & & \\
\hline & Tamat SD & 8 & 9 & 6 \\
\hline & Tamat SMP & 2 & 1 & 4 \\
\hline \multirow[t]{3}{*}{3.} & Jumlah Tanggungan Keluarga & & & \\
\hline & $0-2$ & 3 & 2 & 2 \\
\hline & $3-5$ & 7 & 8 & 8 \\
\hline \multirow[t]{4}{*}{4.} & Pengalaman Usahatani & & & \\
\hline & $1-15$ & 3 & 4 & 4 \\
\hline & $16-30$ & 4 & 4 & 4 \\
\hline & $>30$ & 3 & 2 & 2 \\
\hline
\end{tabular}

Sumber : Data Primer (2020).

Responden penelitian masing-masing komoditas berjumlah 10 petani. Sebagian besar dari petani berumur masih produktif yaitu usia antara 15-64 tahun. Pada usia produktif biasanya petani masih memiliki motivasi yang tinggi, kemampuan yang baik dalam melakukan usahataninya. Petani sebagian besar hanya tamat pendidikan sampai sekolah dasar. Tingkat pengetahuan petani tidak banyak didapat dari pendidikan formal tetapi kebanyakan petani mendapatkan pendidikan dan pelatihan pada lembaga informal terutama yang berkaitan dengan usahataninya. Jumlah tanggungan keluarga yang cukup banyak menjadikan petani merasa kesulitan dalam mengelola keuangan keluarga. Dari lamanya berusahatani nampaknya petani sudah memiliki pengalaman yang banyak mengenai usahataninya.

\section{Usahatani Padi}

Penanaman padi dilakukan dua kali dalam satu tahun. Musim Tanam I antara bulan November- Januari dan musim tanam II antara bulan Mei-Juli. Petani dikelurahan karyamulya menggunakan pola tanam jajar legowo. Varietas padi umumnya yang ditanam adalah Ciherang, Inpari, dan Mitongga. Harga padi kering Rp 5.000/Kg. Luas lahan yang digunakan untuk usahatani padi akan mempengaruhi produktivitas padi yang dihasilkan. Semakin luas lahan yang digunakan untuk membudidayakan padi, maka akan semakin banyak pula produksi yang dihasilkan. semakin luas lahan yang dimiliki para petani responden maka memiliki potensi yang lebih besar untuk menghasilkan produksi yang lebih besar juga. Hal ini sesuai dengan pendapat Suratiyah (2006), bahwa luas lahan dapat menunjukkan besarnya kemungkinan hasil produksi, dimana semakin luas lahan maka semakin besar kemungkinan hasil produksinya. Luas lahan yang digunakan untuk usahatani padi paling luas 
adalah $2.500 \mathrm{~m}^{2}$ dan yang paling kecil adalah $1.500 \mathrm{~m}^{2} .10$ responden rata- rata memiliki luas lahan yang digunakan untuk usahatani adalah seluas $2.340 \mathrm{~m}^{2}$.

Biaya-biaya yang dikeluarkan oleh responden selama melakukan kegiatan usahatani padi dalam 2 kali musim dalam 1 tahun produksi di Kelurahan Karyamulya terdiri dari biaya tetap dan biaya variabel. Biaya tetap yang digunakan dalam usahatani padi merupakan biaya yang diperhitungkan biaya sewa lahan yang tidak semua petani menyewa lahan untuk membudidayakan padi, selain biaya- biaya yang diperhitungkan selanjutnya ada biaya penyusutan, yaitu biaya peralatan yang digunakan dan memiliki umur ekonomis atau tidak sekali pakai, sedangkan untuk biaya variabel yang digunakan untuk satu periode produksi meliputi biaya bahan baku, biaya sarana produksi pertanian dan biaya tenaga kerja.

\section{Usahatani Kangkung}

Penanaman kangkung dilakukan 10-11 kali panen dalam 1 tahun. Benih yang digunakan masyarakat Kelurahan Karyamulya dalam berusahatani kangkung adalah benih kangkung darat yang dibeli di toko pertaniaan. Harga kangkung yaitu Rp 5.000/kg. Masyarakat memilih benih merek Bangkok LP-1 Cap Panah Merah karena selain memiliki harga yang murah, benih tersebut juga memiliki kualitas yang sangat bagus. Luas lahan yang digunakan untuk usahatani Kangkung akan mempengaruhi produktivitas kangkung yang dihasilkan. Semakin luas lahan yang digunakan untuk membudidayakan Kangkung maka akan semakin banyak pula produksi yang dihasilkan. Luas lahan yang digunakan untuk usahatani kangkung paling luas adalah $500 \mathrm{~m}^{2}$ dan yang paling kecil adalah $400 \mathrm{~m}^{2} .10$ responden rata- rata memiliki luas lahan yang digunakan untuk usahatani adalah seluas $440 \mathrm{~m}^{2}$. Biaya yang dikeluarkan oleh responden selama melakukan kegiatan usahatani kangkung dalam 10-11 kali musim dalam 1 tahun produksi di Kelurahan Karyamulya terdiri dari biaya tetap dan biaya variabel.

\section{Usahatani Bunga Kingkong}

Penanaman bunga kingkong dilakukan 4 kali panen dalam 1 tahun. Harga bunga Kingkong Rp 10.000/Kg karena bunga kingkong merupakan bunga yang sangat langka. Pupuk yang digunakan petani dalam berusahatani bunga kingkong diantaranya pupuk Urea, KCL, Phonska, dan Pupuk Kandang. Pemupukan dilakukan agar dapat menyuburkan tanaman, biasanya petani mencampur jenis pupuk tersebut sehingga reaksinya sangat cepat dan tanaman menjadi subur. Luas lahan yang digunakan untuk usahatani Kangkung akan mempengaruhi produktivitas bunga kingkong yang dihasilkan. Semakin luas lahan yang digunakan untuk membudidayakan bunga kingkong maka akan semakin banyak pula produksi yang dihasilkan.Luas lahan yang digunakan untuk usahatani bunnga kingkong paling luas adalah $500 \mathrm{~m}^{2}$ dan yang paling 
kecil adalah $300 \mathrm{~m}^{2} .10$ responden rata- rata memiliki luas lahan yang digunakan untuk usahatani bunga kingkong adalah seluas $400 \mathrm{~m}^{2}$.

\section{Biaya Usahatani Padi, Kangkung dan Bunga Kingkong}

Biaya usahatani terdiri dari biaya tetap dan variabel. Biaya tetap. Biaya tetap yang digunakan dalam usahatani padi, kangkung dan bunga kingkong terdiri dari biaya sewa lahan, biaya penyusutan, sedangkan untuk biaya variabel yang digunakan untuk satu periode produksi meliputi biaya bahan baku, biaya sarana produksi pertanian dan biaya tenaga kerja. Biaya usahatani padi, kangkung dan bunga kingkong dapat dilihat pada Tabel 3 di bawah ini

Tabel 2. Biaya Usahatani Padi, Kangkung dan Bunga Kingkong

\begin{tabular}{llccc}
\hline No & Komoditas & $\begin{array}{c}\text { Luas Lahan } \\
\left(\mathbf{m}^{\mathbf{2}}\right)\end{array}$ & $\begin{array}{c}\text { Biaya } \\
\mathbf{( R \mathbf { p } /} \\
\text { Tahun) }\end{array}$ & $\begin{array}{c}\text { Biaya (per tahun } \\
\left.\text { per 100 } \mathbf{~ m}^{\mathbf{2}}\right)\end{array}$ \\
\hline 1 & Padi & 2.340 & 8.196 .598 & 373.103 \\
2 & Kangkung & 440 & 9.246 .246 & 2.105 .795 \\
3 & Bunga & 400 & 5.285 .269 & 1.340 .037 \\
\hline & Kingkong & Jumlah & 3.818 .935 \\
\hline
\end{tabular}

Sumber: Data Primer Diolah (2020)

Tabel 3 menunjukkan bahwa biaya usahatani tertinggi pada usahatani kangkung yaitu sebesar Rp 2.105 .795 per tahun per $100 \mathrm{~m}^{2}$ (41\%), kemudian biaya usahatani pada usahatani bunga kingkong yaitu sebesar Rp 1.340 .037 (35\%) per tahun per $100 \mathrm{~m}^{2}$ dan biaya paling rendah pada usahatani padi yaitu sebesar Rp 373.103 per tahun per $100 \mathrm{~m}^{2}$ (24\%). Kondisi diatas berkaitan dengan luas lahan dan harga input dimana jika lahan semakin lebih luas maka biaya usahatani persatuan $\left(\mathrm{m}^{2}\right)$ cenderung lebih kecil dan jika harga inputnya lebih tinggi maka biaya usahataninya juga cenderung lebih tinggi.

\section{Pendapatan Usahatani Padi, Kangkung dan Bunga Kingkong}

Harga jual untuk tanaman padi adalah Rp 5000/kg. , harga jual kangkung Rp 5000/kg, dan harga jual bunga kingkong adalah Rp 10.000/kg. Hasil produksi rata-rata per $100 \mathrm{~m}^{2}$ dari padi adalah 156,6 kg, kangkung $562 \mathrm{~kg}$ dan bunga kingkong adalah $415 \mathrm{~kg}$. sehingga penerimaan masing-masing komoditas dapat diketahui. Pendapatan atau keuntungan dari ketiga komoditas dapat dilihat dalam Tabel 4 di bawah ini. 
Tabel 4. Pendapatan Usahatani Padi, Kangkung dan Bunga Kingkong

\begin{tabular}{llccc}
\hline No & Komoditas & $\begin{array}{c}\text { Luas } \\
\text { Lahan } \\
\left(\mathbf{m}^{\mathbf{2}}\right)\end{array}$ & $\begin{array}{c}\text { Penerimaan } \\
(\mathbf{R p} / \text { Tahun/1) }\end{array}$ & $\begin{array}{c}\text { Pendapatan } \\
(\text { per tahun } \\
\left.\text { per } \mathbf{1 0 0} \mathbf{~ m}^{\mathbf{2}}\right)\end{array}$ \\
\hline 1 & Padi & 100 & 783.000 & 409.897 \\
2 & Kangkung & 100 & 2.810 .000 & 704.205 \\
3 & $\begin{array}{l}\text { Bunga } \\
\text { Kingkong }\end{array}$ & 100 & 4.150 .000 & 2.809 .963 \\
\hline & Jumlah & & $\mathbf{3 . 9 4 0 . 6 4 7}$ \\
\hline
\end{tabular}

Sumber: Data Primer Diolah (2020).

Berdasarkan data di atas terlihat bahwa dalam jumlah lahan yang sama yaitu $100 \mathrm{~m}^{2}$, petani bunga kingkong memperoleh pendapatan yang lebih tinggi dibandingkan petani komoditas padi dan kangkung. Hasil produksi ketiga komoditas tersebut dalam luas lahan yang sama berbeda. Hasil produksi padi lebih rendah dibandingkan kedua komoditas lainnya. Yang menjadikan usahatani bunga kingkong keuntungannya lebih banyak dibanding komoditas lain adalah harga jual yang tinggi. Namun walaupun begitu, petani masih kesulitan dalam menanam bunga kingkong. Kendala petani dalam menanam bunga kingkong adalah modal, kebutuhan tanaman hias banyak dipengaruhi oleh musim, ketersediaan lahan dan teknologi yang masih kurang.

\section{Kesimpulan}

\section{KESIMPULAN DAN SARAN}

Berdasarkan hasil penelitian dan pembahasan diatas maka dapat ditarik kesimpulan sebagai berikut:

1. Biaya rata-rata per tahun $/ 100 \mathrm{~m}^{2}$ pada usahatani di Kelurahan Karyamulya Kecamatan Kesambi Kota Cirebon untuk komoditas kangkung yaitu sebesar Rp 9.246.246 (41\%), kemudian bunga kingkong yaitu sebesar Rp 1.340.037 (35\%) dan yang paling rendah komoditas padi yaitu sebesar Rp 373.103 (24\%), sedangkan pendapatan rata-rata tertinggi pada usahatani bunga kingkong per tahun/100 $\mathrm{m}^{2}$ yaitu sebesar Rp 2.809.963 kemudian kangkung yaitu sebesar Rp 704.205 dan terendah pada usahatani padi yaitu sebesar Rp 409.897.

2. Terdapat perbedaan biaya dan pendapatan rata-rata per tahun/100 $\mathrm{m}^{2}$ pada usahatani padi dengan kangkung dan bunga kingkong, juga kangkung dengan bunga kingkong di Kelurahan Karyamulya Kecamatan Kesambi Kota Cirebon.

\section{Saran}

Berdasarkan kesimpulan penelitian maka yang dapat disampaikan saransaran sebagai berikut: 
1) Kepada Petani, disarankan:

Untuk meningkatkan pendapatan pada usahatani di Kelurahan Karyamulya Kecamatan Kesambi Kota Cirebon maka disarankan untuk melakukan budidaya bunga kingkong melalui intensifikasi, yaitu upaya meningkatkan produksi bunga kingkong dengan tidak menambah luas lahan.

2) Kepada Peneliti lain, disarankan:

Agar dapat melakukan penelitian sejenis pada daerah lain sehingga dapat memperluas pengetahuan tentang studi komparatif komoditas pertanian.

3) Kepada Petugas Penyuluh Pertanian, (PPL) Setempat, disarankan: Agar dapat mensosialisasikan teknik budidaya komoditas bunga kingkong beserta pendapatannya karena komoditas ini yang lebih menguntungkan.

\section{DAFTAR PUSTAKA}

Adfa, M., \& Kasrina. (2001). Pacar air (Impatiens spp.) sebagai Tanaman Obat Masyarakat Bengkulu: Survey Etnobotani dan Keanekaragaman hayati.

Anggraini. (2013). Sistem Tanam dan Umur Bibit pada Tanaman Padi Sawah (Oryza sativa L.) Varietas Inpari 13. Jurnal Produksi Tanaman, 1(2), 52-60.

Asri, N. (2005). Kemiskinan Petani. Sekolah Tinggi Ilmu Pertanian. Creswell, J. (2010). Reseach Design: Pendekatan Kualitatif, Kuantitatif, dan Mixed. Pustaka Pelajar.

Dinas Pangan Pertanian Kelautan dan Perikanan. (2019). Jumlah Produksi dan Luas Panen Produksi Padi, Kangkung dan Bunga kingkong Pada Tahun 2018- 2019.

Sugiyono. (2007). Metode Penelitian Pendidikan Pendekatan Kuantitatif, Kualitatif, dan RED. Alfabeta. 